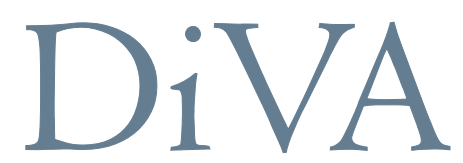

http://uu.diva-portal.org

This is an author produced version of a paper published in Patient Education and Counseling. This paper has been peer-reviewed but does not include the final publisher proof-corrections or journal pagination.

Citation for the published paper:

Jangland, Eva, Gunningberg, Lena, Carlsson, Maria

'Patients' and relatives' complaints about encounters and communication in health care: Evidence for quality improvement"

Patient Education and Counseling, 2009, 75, 2: 199-204

DOI: 10.1016/j.pec.2008.10.007

Access to the published version may require subscription.

Published with permission from: Elsevier 


\title{
Patients' and relatives' complaints about encounters and communication in health care: evidence for quality improvement
}

\author{
Eva Jangland, RN, MSc, PhD student ${ }^{13}$, Lena Gunningberg, RN, $\underline{\text { Associate } \text { Professor }^{2}}$ \\ ${ }^{3}$ and Maria Carlsson, RN, $\underline{\text { Associate Professor }}{ }^{4}$ \\ ${ }^{1}$ Department of Surgery, University Hospital, Uppsala, Sweden \\ ${ }^{2}$ Surgery division, University Hospital, Uppsala, Sweden \\ ${ }^{3}$ Department of Surgical Sciences, Uppsala University, Sweden \\ ${ }^{4}$ Department of Public Health and Caring Sciences, Uppsala University, Sweden
}

Correspondence to:

Eva Jangland

Department of Surgery, ing 70

Uppsala University hospital

SE - 75185 Uppsala

Sweden

Phone 46196113722

Fax $+46(0) 18559410$

eva.jangland@surgsci.uu.se

Word count: Abstract 194. Manuscript 4391 (abstract, references and table excluded). 
Objective. The aim of this study was to describe patients' and relatives' complaints to the local Patients' Advisory Committee about their encounters and communication in health care.

Methods Complaints ( $\mathrm{n}=105)$ regarding patients' and relatives' dissatisfaction with communication and encounters in health care, registered at a local Patients' Advisory Committee between 2002 to 2004, were included. The texts were analysed using content analysis.

Results Three categories were identified: "Not receiving information or being given the option to participate", "Not being encountered in a professional manner" and "Not receiving nursing or practical support”. Insufficient information, insufficient respect and insufficient empathy were described as the most common reasons for a negative professional encounter.

Conclusion Patients and relatives experienced unnecessary anxiety and reduced confidence in health care after negative professional encounters.

Practice implications The complaints reported to the Patients' Advisory Committee could be used more effectively in health care and be regarded as important evidence when working with quality improvement. To systematically use patient stories, such as those obtained in this report, as a reflective tool in education and supervision could be one way to improve communication and bring new understanding about the patient's perspective in health care.

\section{Keywords}

Complaints, communication, professional encounter and content analysis. 


\section{Introduction}

High quality in the communication with the patient is important during medical treatment as well as in nursing to reach patient satisfaction. Studies that describe quality of care from the patient's perspective list good relations with health professionals and adequate information as important factors for both patients and relatives [1-5].

The interaction between the patient and the professional is a dyadic, and the outcome is influenced by many different factors. A communication framework, described by Feldman-Stewart et al [6-7] consists of four main components that occur between the patient and the health professional. These are as follows: first, the focus of the interaction including each participant's communication goals; second, the participants themselves - the patient's and professional's needs, skills, values, beliefs and emotions that affect the communication; third the communication process including how messages are verbally and non-verbally conveyed and received; and fourth the environment in which the communication occurs, also including external factors such as education, expectations and personal experiences.

Much research has been done on communication between patients and health professionals. For example, the power of the information communicated by the voice was studied among surgeons, and it was suggested that "how" a message is conveyed may be as important as "what" is said [8]. The physician-patient communication was studied among primary care physicians and surgeons. Physicians with no-claim seemed to conduct longer visits, educate patients more, check understanding more and use more humour during the visit than physicians with claims [9]. A study by Kuzel [10] showed that negative outcomes in the clinician-patient relationship, dominated by stories of disrespect or insensitivity, were reported as more common than technical errors in diagnosis and treatment.

The Institute for Healthcare Improvement (IHI) emphasizes that the health care system needs to be more patient-centred and to involve the patients and families in the design of care. Patient-centred care requires respect for patients' values and expressed needs, information and communication, coordination of care, involvement of family, 
and concordance between the patient and health professionals [11]. Eldh [12] concludes that health care professionals should support patient participation by recognizing the patient as an individual and as a resourceful partner. The benefits of patient-centred care could be that patients are more motivated to follow treatment advice [13] and are more satisfied with health care [14].

Patient satisfaction is used as a common quality indicator in health care [15-16]. A problem using patient satisfaction as a quality indicator depends on the complexities where different factors could affect the outcome, and the reliability and validity questioned [17]. Factors such as gratitude, faith and loyalty to health care providers, could influence patient satisfaction [18] as well as background factors such as age, health status and expectations of care [19-20]. A patient's evaluation could be positive, even when care is poor [18]. Some researchers think that studying patient "dissatisfaction" is a more valuable concept than studying patient "satisfaction" [2122].

In Sweden there is a nationwide organisation for handling patients who are not satisfied with the health care. Both patients and relatives have the possibility of contacting their Patients’ Advisory Committee, located in every county council, to ask questions or to report unsatisfactory conditions. The committees act on the patients' or relatives' behalf. The complaints are filed in an electronic system, used nationwide, in different categories depending on the content: “care and treatment”; “organisation, regulations and resources”; and "encounters and communication”. Each complaint is investigated by the committee and feedback is given to each involved health professional as well as the head at the department, who have the possibility to respond. However no comprehensive summary of the complaints is reported to the organization. Statistics show that reported complaints to Patient Advisory Committees regarding the quality of health care have increased from about 22,500 complaints in 2002, to about 25,000 complaints in 2006. If a case needs to be investigated further, patients could file an application to The Health and Medical Care Liability Board or to the Patient Insurance Company. These two procedures are independent, and the claims for financial compensation in case of patient injury in the medical treatment can be taken without the need for identifying a particular professional [23-24]. 
Despite the national system to categorize the complaints at the Patient Advisory Committee, categories are too broad to be helpful for the departments in their improvement of health care. No detailed analysis has been conducted for the category "encounters and communication". The patients or relatives in this study have made a conscious decision to report their dissatisfaction with professional encounters and are valuable sources for the health care organisation when working with quality improvement. Complaints and dissatisfaction with health professionals are often perceived negatively by health professionals; however, they could be turned to advantage and transformed into a valuable improvement tool. The aim of this study was to describe patients' and relatives' complaints to the local Patients' Advisory Committee about their encounters and communication in health care.

\section{Methods}

\subsection{Sample and setting}

The study took place in a university hospital in Sweden. The hospital offers specialised medical and nursing care, and has 1100 beds. The hospital has 55,000 admissions and more than 710,000 out-patient visits yearly, and serves patients from the local area as well as central Sweden. Some specialities also provide medical treatment for patients from other parts of the country and abroad.

From 2002 to 2004, 1784 complaints were reported to the local Patients’ Advisory Committee about the quality of care at the university hospital. A total of 194 complaints concerned unsatisfactory "encounters and communication” registered in the electronic system. Of these 105 complaints were retrospectively included in this study. The complaints that were excluded were too brief to allow for content analysis. They consisted only of a short sentence such as "bad encounters" and no further description about the experience. The text in the included complaints varied from a few sentences in telephone calls to long letters with careful descriptions about the experiences of encounters with health professionals. In both cases the person is asked to tell the story and describe the event in their own words. In the telephone documentation the story is written down so that it is as close as possible to the story told by the patient or relative. The reports included were filed by patients $(n=54)$, 
relatives ( $n=47)$ and others $(n=4)$ and consisted of documentation from telephone calls $(n=72)$, letters $(n=28)$, electronic mail $(n=3)$ or visits to the committee $(n=3)$.

\subsection{Procedure}

All electronic reports concerning dissatisfaction with encounters and communication during the study period were reviewed in detail by the first author. The reports without any personal information were copied. This part of the study took place at the local Patients’ Advisory Committee together with the head of the committee. During the analysis a word document was created for the study, and the analysis was performed in the document.

\subsection{Data analysis}

Content analysis according to Krippendorff [25] is a research technique for making replicable and valid inferences from texts to the contexts of their use. The method makes it possible to describe the content of the text. In this study the context is the patients and relatives that reported experience of dissatisfaction with professional encounters in different care settings to the local Patients' Advisory Committee. The aim in qualitative descriptive studies is to discover the basic nature and shape of events or experiences, and in the description stay close to data [26].

The analysis was performed using the steps described by Graneheim \& Lundman [27] and Berg [28]. The manifest content were considered during the analysis [27].

- All reports were read through several times to get a sense of the whole.

- Meaning units were extracted from the text.

- An abstraction of the meaning units into codes was created.

- The various codes were read and re-read and compared against each other. Based on this reading and a reflective process the codes were sorted into subcategories.

- The next step in the analysis was to count the occurrence of each sub-category in the reports. A single report could contain more than one sub-category.

- The sub-categories were compared with each other and with the original text to create mutually exclusive categories. 
- An independent analysis of all the reports was performed by each of the two co-authors. All authors discussed the categorisation and the content of the categories and consensus about the categorization was reached.

\subsection{Ethical considerations}

The research was approved by the head of the Patients' Advisory Committee in the county council where the study took place, and followed the principles in the Declaration of Helsinki [29]. Since the study did not include any intervention, no permission from the Ethics Committee was needed. All reports were treated confidentially and anonymously with respect to the patient, relative, department and health professional.

\section{Results}

The analysis resulted in three categories in which the patients or the relatives described dissatisfaction with the professional encounters during their visit or stay at the hospital: "Not receiving information or being given the option to participate", "Not being encountered in a professional manner" and "Not receiving nursing or practical support”. The categories contain 14 sub-categories. Complaints occurred throughout all parts of the visit or stay and included different departments as well as different health professionals. Table 1 provides an overview of the categories and the sub-categories. The content of the sub-categories is described and exemplified with quotations.

Insert table 1 about here

\subsection{Not receiving information or being given the option to participate}

Insufficient information was the most common dissatisfaction about negative professional encounters. Patients described that they received insufficient information during the examination or when the diagnosis was given, or they felt the information was misleading. Lack of physician continuity was reported either concerning information on the diagnosis or when treatment and care were planned. Patients felt insecure when they received different information from several physicians. Patients 
described not receiving the results of tests and treatment within a reasonable timeframe. Insufficient or lack of information leads to unnecessary anxiety.

"A nurse promised that the doctor would call me about the test results. Nobody got in Kommentar [E2]: Skall kontrollera touch with me! I tried to convince myself that everything was as it should be. After two grunddata om pat använder ordet oro. more weeks I called the hospital again to ask about the results. To have to call time and again as a patient makes me feel like a nuisance...” (patient, report 1)

Relatives gave descriptions of insufficient information about the diagnosis and insufficient information about deterioration of the patient's health. Mostly these reports described the palliative phase and the period after the patient's death. Relatives lacked information about the patient's last moments in life, cause of death and the autopsy results.

In the sub-category insufficient exchange of information between health professionals, patients described that the health professional did not have adequate information about their state of health. The health professional had not read the patient record or there was insufficient exchange of information between professionals.

"When speaking with the nurse over the telephone on several occasions, I have felt as if I as a patient have to stay up to date and know what the next step in treatment will be. This has been frustrating!” (patient, report 82)

Some patients experienced that they had not been given the option to participate in decision about whether they wanted to participate in $a$ teaching situation with students or not. Other patients experienced that they were not allowed to discuss the treatment with the physician and to participate in the conversation or the medical decision. Several accounts are given of patients who did not understand information given due to difficulty speaking or understanding the Swedish language. In some cases, patients were not provided with an interpreter even though relatives had asked for one.

In the sub-category - inappropriate conversation environment - some patients and relatives reported that they were not provided with privacy when they received 
information about their diagnosis or other sensitive information. The information was given in a care room with other patients listening or in the corridor.

"Since there was a patient next to us separated only by a curtain, we had no private sphere for our conversation with the doctor. We could hear when the doctor gave the other patient information about his diagnosis...” (relative, report 16)

\subsection{Not being encountered in a professional manner}

Many complaints related to the fact that patients and relatives perceived that health professionals did not approach the patient or family member in a professional manner. Insufficient respect was shown to the patient or relative, such as nonchalance or indifference to time, by health professionals. Some patients experienced nonchalance when health professionals did not answer questions or demonstrated nonchalant behaviour, for example laughing at the patient or mumbling so that the patient was unable to understand the conversation. A number of patients described a nonchalant attitude when they were not given an explanation for a delayed appointment. Relatives described nursing situations in which the nursing staff talked in a condescending way about the patient.

"The personnel who got things in order before my husband's transfer to a hospice spoke to each other as if he wasn't there, and I felt a lack of respect for my husband and for me as his wife. It felt they treated my husband as if he were already dead." (relative, report 45)

Patients with a diagnosis of cancer reported that the physician informed them of the diagnosis without showing empathy. Examples of insufficient empathyincluded information regarding a cancer diagnosis being given when the patient was alone without the opportunity to have a relative present, or when patients were given critical information hurriedly during a ward round. Patients with chronic diseases received comments from staff such as "pull yourself together” or "look ahead”.

“I was told 'there's nothing we can do'. The information was given without feeling and with a complete lack of empathy and concern...” (patient, report 42) 
In the sub-category insufficient acknowledgement several patients described that they did not feel welcome because nobody knew who they were. Others said that that they were not listened to seriously when they tried to describe their problems. Some patients, with acute illness, described a feeling of loneliness and being abandoned when they were left alone in an examination room. Relatives described situations when the patient was in a palliative phase or was seriously ill and they felt that nobody acknowledged them or asked how they felt. Other relatives said that they were not noticed or addressed when they accompanied the patient to an appointment or an examination.

In the sub-category poor conversation skills, patients were dissatisfied when the health professional did not introduce himself, did not shake hands, did not make eye contact during the conversation, or was interrupted by the telephone several times. Patients also gave examples in which the physician walked around in the room during the conversation, the door was left open or the physician began to shout, projecting his irritation towards the patient.

“The doctor came into the room without shaking hands or greeting me and didn't make eye contact at any time during the conversation.” (patient, report 2)

Some patients described situations in which they felt that health professionals had abused their position and this caused anxiety and offence. Aggressive attitudes, displays of irritation and even threats were reported. Patients said that they felt frightened, did not ask for more information and felt that they were an annoyance. As a consequence, the encounters led to inadequate information and insufficient nursing.

"I ring the call button. The nurse comes in, shuts off the call button and leaves. She shows her aggression. I feel totally abandoned and afraid. I'm afraid and yell:

Sorry.” (patient, report 34)

A patient visited an out-patient clinic to perform a test before he was going to receive a certificate, describes the experience in this quotation. 
"The doctor says to me: Do not try to trick me. I do not like that. He becomes irritated and threatens to write down something negative if I don't hurry up. During the examination, the doctor makes me feel stressed and screams for me to answer, before I've even had a chance to think or respond." (patient, report 76)

A mother visited an out-patient clinic with her daughter needed information about the waiting time, describes her experience in this quotation.

Då jag frågar svarar hon i mycket a vsnoppande ton att mina frågor sinkar henne och att det tar mycket längre tid om hon måste stå här och prata med mig. Hon uppträder kraftigt nedlåtande och irriterat ."Condescending, snubbing retorts coming from people I am dependent on make me lose faith in the hospital...” (relative, report 10)

Furthermore, relatives experienced lack of emotional support when they were in a crisis situation because their next-of-kin was seriously ill or in a palliative phase. Insufficient emotional support was reported by relatives who were given serious information in an insensitive way. Some were not offered any professional support. They explained in the reports that they had needed time to grieve, but that they constantly returned to unanswered questions and their own unsatisfactory experiences from the hospital. Some relatives were satisfied with the medical treatment, but dissatisfied with the emotional support they received.

“They answered our questions reluctantly and showed no sympathy for our situation. I keep remembering the days on the ward when the children and I felt alone and exposed in a way we never thought possible... We talked to a priest the first evening, but after that we didn't receive any professional help in dealing with our crisis..." (relative, report 43)

Some descriptions appear in the reports in which the patient experienced discrimination from health professionals. They felt they were treated poorly due to their immigrant background. 


\subsection{Not receiving nursing or practical support}

Some complaints were related to disappointment with nursing and practical support. Insufficient nursing includes descriptions by patients, when not receiving anything to eat for a whole day, being refused assistance to the toilet and not receiving help to take care of personal hygiene.

"I was placed in a single room. The personnel were hurried and unpleasant. I would have preferred to have company because I was having difficulty breathing. One of the assistants told me they didn't have enough personnel for that. Nobody paid attention to me for a long time and I didn't get anything to drink...” (patient, report 103)

Insufficient practical support is described as not being helped with practical tasks such as calling for a taxi, but also as a relative, when being in a crisis situation, as not getting help to find a temporary place to stay within the hospital.

\section{Discussion and conclusion}

\subsection{Discussion}

Insufficient information, insufficient respect and insufficient empathy were the most common complaints related to professional encounters and communication. Several patients stated that one of the reasons for filing a complaint was an expectation that their experience would lead to improvements and that no other patient should have to endure the same anxiety. These findings are according to the results by another Swedish study [30], where they conducted narrative interviews with six patients who had reported dissatisfaction with hospital care.

The key components in the framework by Feldman-Stewart [6-7] are helpful when Patient Advisory Committee (Eriksson och swedberg använder förkortningen PAC vilket du också borde göra, då får du ner antalet ord något!) analysing and trying to understand the reasons for a negative outcome in the present study. Many complaints could be easily avoided with improved communication technique and changed attitudes among health professionals.

To improve quality in care the concept of patient-centred care and patient participation need to be discussed and given high priority within the organisation [1112]. Studies describe the advantages of using patient-centred care [13-14, 31]. For 
example the patients were more satisfied when they were involved in the consultation with the physician or the nurse [14, 32]. However, it should also be remembered that patient preferences differ regarding participation in clinical decision making. The majority of the patients who were admitted to acute hospital care preferred adopting a passive role in clinical decision making, at least in the initial phase [33]. It is possible that the negative encounters in our study could be explained by the fact that the patient and the professionals had different goals, needs and expectations related to the encounter. This could probably be addressed by the professionals when starting the dialogue, asking the patient or the relative about his or her specific goals or expectations according to the communication framework [6-7].

Relatives expressed a lack of information and participation, especially in caring for seriously ill patients, or dying patients and after the patient's death. Studies have demonstrated the importance for relatives of dying patients to be given sufficient information about the patient's situation, to be involved in the patient's care and to be offered support for their own difficult situation [34-35] Eriksson \& Lauri [36] pointed out that relatives' need for information was greater than their need for emotional support, which also emphasizes the importance of communication goals $[6,7]$.

Insufficient acknowledgement was described by patients in terms of insufficient respect and not being seen as a unique person. Patients and relatives believed that lack of time and the high workload for health professionals was one explanation for these situations, but it was not accepted as an excuse for such behaviour. Kindness, humanity, and respect are identified as the core values of medical professionalism [37], but often overlooked in a time pressured health care. Health professionals have a crucial influence on how patients experience dignity. Patients' dignity could be either threatened or supported depending on the type of encounter the health professional use [32]. Threatening a patient's dignity was described in some reports in the present study when professionals abused their position in relation to the patient. As a consequence of this behaviour the patients did not receive the information and care they needed, and some patients were offended by the encounter. Studies have shown that regardless of the reason for uncaring encounters the experience is significant for the patient [1-3]. Lack of time and differences of opinion among health professionals 
are sometimes unavoidable, but should not burden patients and relatives. Besides the personal anxiety for the individual patient, an inadequate professional encounter could also be a threat to patient safety. If the patient does not understand the information and finds it difficult to ask questions he might, for example, not prepare himself adequately before surgery or take medicine in a proper way.

Many encounters in the daily activities for health professionals include dealing with difficult events, difficult patient's relations and ethical dilemmas, and it is important to have the opportunity to discuss these with colleagues. To strengthen the professionals [6-7], different approaches could be arranged within the organisation, such as clinical supervision [38] or "ethics rounds", which is organized ethical group discussions [39]. Often heavy workloads do not allow for organized reflection and discussions. It is important for leaders to understand their value and prioritize this kind of activities in a long-term perspective [40] thereby improving quality in patient care [41-42].

Rycroft-Malone et al [42-44] suggest that patient experiences should be regarded as an important source for evidence in quality improvement. In Sweden the organisation for reporting complaints to the Patients' Advisory Committee is well known by the patients, and the complaints could be a complement to patient questionnaires about the quality of care. However, the complaints need to be analyzed and presented so that they can be used more easily in discussions within the organisation. A summary of patients' complaints at regular intervals, using the categorisation scheme in this study, as well as unidentified patient stories, could contribute as useful and valuable feedback of evidence to the organisation.

One might argue that the number of complaints reported to the Patients' Advisory Committee was small compared to all inpatient admissions and outpatient clinic visits taking place at the university hospital. However, these patients and relatives have made a conscious decision to evaluate the care, and the information should be regarded as having high validity [22]. One limitation is the fact that the complaints already were pre categorized at the committee. Furthermore, if a complaint included aspects about the medical treatment as well as the encounters and the communication, it was filed in the category "care- and treatment” at the committee. Therefore, it is 
possible that there were more complaints about encounters and communication. In the timeframe of this study, it was not possible to include all reports. Another limitation was the number of drop-outs identified as telephone reports with descriptions too short for content analysis. On the other hand, the reports included in the study had detailed descriptions that were appropriate for the analysis. Probably the findings from the present study are not specific/unique (?) for only this hospital, but could be transferred to similar contexts [27, 45].

Some patients gave descriptions of recurrent negative encounters during the hospital stay or the out patient visit. It seems like it was the last straw that made the patient file a report to the local Patients' Advisory Committee. In further research, it would be interesting to conduct interviews with patients who have contacted the committee to reach a deeper understanding about the issue from the patient's perspective.

\subsection{Conclusion}

Insufficient information, insufficient respect and insufficient empathy were the most common complaints related to professional encounters and communication. Patients and relatives experienced unnecessary anxiety and reduced confidence in health care after negative professional encounters. Health professionals need to understand the patient's perspective and the consequences of a negative encounter for the individual patient or relative.

\subsection{Practice implications}

The complaints reported to the Patients' Advisory Committee could be used more effectively in health care and be regarded as important evidence when working with quality improvement. The categorisation scheme from this study could be useful to make the feedback from the system more intelligible. To systematically use patient stories, such as those reported here, as a reflective tool in education and supervision could be one way to improve the communication and bring new understanding about the patient's perspective in health care. An educational programme has been developed at the university hospital, based on the content from reports to the Patients' Advisory Committee. The programme (computer and paper based) is used at the 
hospital to start discussions and introduce the patient perspective in education and supervision of both students and health professionals.

\section{Acknowledgements}

We acknowledge Eva Åkerlind, the head of the local Patients’ Advisory Committee, and Ewa Lundgren, the head of the Department of Surgery for their support and encouragement.

We confirm all patients and personal identifiers have been removed or disguised so the persons described are not identifiable and cannot be identified through the details of the story.

Funding

None

Conflict of interest

None known 


\section{References}

[1] Halldorsdottir S, Hamrin E. Caring and uncaring encounters within nursing and health care from the cancer patient’s perspective. Cancer Nurs 1997;20:120-8.

[2] Attre M. Patients' and relatives' experiences and perspectives of 'good' and 'not so good'quality care. J Adv Nurs 2000;33:456-66.

[3] Arman M, Rehnsfeldt A, Lindholm L, Hamrin E, Eriksson K. Suffering related to health care: A study of breast cancer patients' experiences. Int J Nurs Pract 2004;10:248-56.

[4] Schattner A, Rudin D, Jelllin N. Good physicians from the perspective of their patients. BMC Health Serv Res 2004;4.

[5] Pelander T, Leino-Kili H. Quality in paediatric nursing care: Children's expectations. Issues Compr Pediatr Nurs 2004;27:139-51.

[6] Feldman-Stewart D, Brundage MD, Tishelman C. A concepual framework for patient-professional communication: An application to the cancer context. Psychooncology 2005;14:801-9.

[7] Carlsson L, Feldman-Stewart D, Tishelman C, Brundage M. Patient-professional communication research in cancer: An integrative review of research methods in the context of a conceptual framework. Psychooncology 2005;14:812-28.

[8] Ambady N, LaPlante D, Nguyen T, Rosenthal R, Chaumeton N, Levinson W. Surgeons' tone of voice: A clue to malpractice history. Surgery 2002;132.

[9] Levinson W, Roter DL, Mullooly JP, Dull VT, Frankel RM. Physician-patient communication. The relationship with malpractice claims among primary care physicians and surgeons. JAMA 1997;277. 
[10] Kuzel AJ, Woolf SH, Gilchrist VJ, Engel JD, LaVeist TA, Vincent C, Frankel R. Patient Reports of Preventable Problems and Harms in Primary Health Care. Ann Fam Med 2004;2.

[11] The Institute for Healthcare Improvement (IHI) Avaliable at http://www.ihi.org/IHI/Topics/PatientCenteredCare/ (accessed December 9 2007).

[12] Eldh A. Patient participation - what it is and what it is not. Doctor Thesis, Örebro Studies in Caring Sciences;2006.

[13] Irwin R, Richardson N. Patient-Focused Care. Using the Right Tools. Chest 2006;130:73-82.

[14] Fossum B, Aborelius E. Patient-centred communication: videotaped consultations. Patient Education and Cons 2004;54:163-9.

[15] Wilde B, Starrin B, Larsson G, Larsson M. Quality of care from a patient's perspective. Scand J Sci 1993;8:113-120.

[16] The Institute for Healthcare Improvement (IHI) Available at http://www.ihi.org/IHI/ (accessed March 15 2008).

[17] Sitzia J. How valid and reliable are patient satisfaction data? An analysis of 195 studies. Int J Qual Health Care 1999;4:319-8.

[18] Staniszewska SH, Henderson L. Patients' evaluations of the quality of care: influencing factors and the importance of engagement. J Adv Nurs 2005;49:530-7.

[19] Ramqvist M. Patient satisfaction in relation to age, health status and other background factors: a model for comparisons of care units. Int J Qual Health Care 2001;5:385-90. 
[20] Sørlie T, Sexton HC, Busnad R, Sørlie D. Predictors of satisfaction with surgical treatment. Int Qual Health Care 2000;12:31-40.

[21] Coyle J, Williams B. Valuing people as individuals: development of an instrument through a survey of person-centredness in secondary care. J Adv Nurs 2001;36:450-9.

[22] Anderson K, Allan D, Finucane P. A 30-month study of patient complaints at a major Australian hospital. J Qual Clin Pract 2001;21(4):109-11.

[23] National Board of Health and Welfare. Patientnämndernas rapportering till Socialstyrelsen. (The Local Patients' Advisories report to the National Board of Health and Welfare -In Swedish) Available at: http//www.sos.se/fulltext/131/2003-131-9/Sammanfattning.htm (accessed 7 June 2007).

[24] The Patient injury act. Available at: http://www.patientforsakring.se/pdf/medicalliability.pdf (accessed December 9, 2007).

[25] Krippendorff, K . Content Analysis. An Introduction to its Methodology, 2nd edition. London: Sage; 2004.

[26] Sandelowski, M. Whatever Happened to Qualitative Description? Res Nurs Health. 2000;23:334-40.

[27] Graneheim UH, Lundman L .Qualitative content analysis in nursing research: concepts, procedures and measures to achieve trustworthiness. Nurse Educ Today 2004;24:105-12.

[28] Berg BL. Qualitative Research Methods for the Social Sciences. Fifth Edition. Pearson Education, Inc;2004. 
[29] World Medical Association Declaration of Helsinki. Avaliable at http://www.codex.uu.se [In Swedish]

[30] Eriksson U, Svedlund M. Struggling for confirmation - patients' experiences of dissatisfaction with hospital care. J Clin Nurs 2007;16:438-46.

[31] Fossum B, Arborelius A, Theorell T. How physicians experience patient consultations at an orthopaedic out-patient clinic: a quality study. Patient Education and Cons 2002;47:127-35.

[32] Friberg F, Pilhammar Andersson E, Bengtsson F. Pedagogical encounters between nurses and patients in a medical ward - A field study. Int J Nurs Stud 2007;44:534-44.

[33] Florin, J. Patient participation in clinical decision making in nursing - a collaborative effort between patients and nurses. Doctor Thesis, Örebro Studies in Caring Sciences; 2006.

[34] Wilkes L, White K, O’Riordan L. Empowerment through information: supporting rural families of oncology patients in palliative care. Aust J Rural Health. 2000;8:41-6.

[35] Andershed B, Ternestedt B-M. Development of a theoretical framework describing relatives' involvement in palliative care. J Adv Nurs 2001;34:554-62.

[36] Eriksson E, Lauri S. Information and emotional support for cancer patients' relatives. Eur J Cancer Care. 2000;20:120-8.

[37] Chochinov H. Dignity and the essence of medicine: the A, B, C and D of dignity conserving care. BMJ. 2008;184-7.

[38] Berggren I, Severinsson E. Nurse supervisors'actions in relation to their decisionmaking style and ethical approach to clinical supervison. J Adv Nurs 2003;41:615-22. 
[39] Hansson MG. Imaginative ethics-bringing ethical praxis into sharper relief. Med Health Care Philos 2002;5:33-42.

[40] Scott-Findlay S, Golden-Biddle K. Understanding how organizational culture shapes research use. JONA's Health, law, ethics and regulation. 2005;35:359-65.

[41] Gustafsson C, Fagerberg I. Reflection, the way to professional development? J Clin Nurs 2004;13:271-80.

[42] Hallina K, Danielsson E. Registered nurses’ experiences of daily work, a balance between strain and stimulation: A qualitative study. Int J Nurs Stud 2007;44:1221-30.

[43] Rycroft-Malone J, Kitson A, Harvey G, McCormack B, Seers K, Titchen A, Esarooks C. Ingredients for change: revisiting a conceptual framework. Qual Saf Health Care 2002;11:174-80.

[44] Rycroft-Malone J, Seers K, Titchen A, Harvey G, Kitson A, McCormack B. What counts as evidence in evidence-based practice? J Adv Nurs 2004;47:8190.

[45] Leininger M. Evaluation criteria and critique of qualitative research studies. In Morse J M. Critical issues in qualitative research methods. Thousand Oaks, Sage Publ. 1994. 
Table 1. Overview of categories and sub-categories, and the number of sub-categories in patients' and relatives' reports $\underline{(\mathrm{n}=105)}$. One report could contain more than one sub-category.

\begin{tabular}{lll}
\hline Categories & \\
and sub-categories & Patients reports & Relatives reports \\
\hline
\end{tabular}

\section{Not receiving information or being given the option to participate}

Insufficient information

30

Insufficient exchange of

information between

health professionals

18

Insufficient participation

13

Difficulty speaking and

understanding the language

8

Inappropriate conversation

environment

3

2

Not being encountered in a professional manner

$\begin{array}{lrr}\text { Insufficient respect } & 29 & 10 \\ \text { Insufficient empathy } & 23 & 7 \\ \text { Insufficient acknowledgement } & 22 & 4 \\ \text { Poor conversation skills } & 9 & 3 \\ \text { Professionals' abuse of position } & 5 & 4 \\ \text { Insufficient emotional support } & 1 & \\ \text { Discrimination } & 3 & \end{array}$

Not receiving nursing or practical support

Insufficient nursing

Insufficient practical support 
